\title{
PEMUPUKAN UREA DAN PACLOBUTRAZOL TERHADAP PERTUMBUHAN TANAMAN JAGUNG MANIS (Zea mays saccharata Sturt.)
}

\author{
UREA FERTILIZATION AND PACLOBUTRAZOL ON GROWTH OF SWEET CORN \\ (Zea mays saccharata Sturt.)
}

\author{
Pemmy Tumewu'), Paula Ch. Supit1), Ridson Bawotong²), Anni E. Tarore1), dan \\ Selvie Tumbelaka ${ }^{1)}$ \\ 1) Jurusan Budidaya Pertanian Fakultas Pertanian Unsrat \\ 2)Badan Pelaksana Penyuluhan Pertanian Perikanan dan Kehutanan Kab.Sitaro
}

\begin{abstract}
The study aims to determine the response of sweet corn plants of urea fertilizer and the provision of Paclobutrazol. Randomized trials using Design Group (RAK) Factorial pattern. The experiments are a factor I (A): Nitrogen fertilizer, Ao = Without fertilization, $A 1=100 \mathrm{~kg} \mathrm{~N} / \mathrm{ha}, A 2=200 \mathrm{~kg} \mathrm{~N} / \mathrm{ha}$, and Factor II (B): The concentration of Paclobutrazol ie, Bo = Without Paclobutrazol, B1 $=500 \mathrm{ppm}, \mathrm{B} 2=$ $1000 \mathrm{ppm}$. Variables observed were: 1) Higher Plants, 2) The number of leaves. Data were analyzed using a variety of analysis followed by LSD $5 \%$. The results showed that the interaction between nitrogen fertilizer and Paclobutrazol is not significant on sweet corn plants but interaction on the number of leaves. Paclobutrazol independently affect the height of sweet corn plants. Giving Paclobutrazol 500 ppm and 1000 ppm to corn plants are shorter than without Paclobutrazol.
\end{abstract}

Keywords: Nitrogen fertilizer, Paclobutrazol, and sweet corn crops

\section{ABSTRAK}

Penelitian bertujuan untuk mengetahui respon tanaman jagung manis terhadap pemupukan urea dan Paclobutrazol. Percobaan acak menggunakan Design Group (RAK) pola faktorial. Percobaan adalah faktor I (A): pupuk Nitrogen e Ao = Tanpa pembuahan, $A 1=100 \mathrm{~kg} \mathrm{~N} /$ ha, $A 2=200 \mathrm{~kg} \mathrm{~N} /$ ha, dan Faktor II (B): Konsentrasi Paclobutrazol yaitu, Bo = Tanpa paclobutrazol, B1 $=500 \mathrm{ppm}, \mathrm{B} 2=1000$ ppm. Variabel yang diamati adalah: 1) Tanaman tinggi, 2) Jumlah daun. Data dianalisis dengan menggunakan berbagai analisis diikuti oleh Uji Perbedaan Terkecil Real (LSD) 5\%. Hasil penelitian menunjukkan bahwa interaksi antara pupuk nitrogen dan Paclobutrazol tidak nyata pada tinggi tanaman jagung manis tapi interaksi nyata pada jumlah daun. Paclobutrazol mempengaruhi tinggi tanaman jagung manis. Pemberian Paclobutrazol 500 ppm dan 1000 ppm memberikan tanaman jagung lebih pendek daripada tanpa Paclobutrazol.

Kata kunci: Pupuk nitrogen, Paclobutrazol, dan tanaman jagung manis 


\section{PENDAHULUAN}

Tanaman jagung manis (Zea mays saccharata Sturt.) atau sweet corn merupakan jenis jagung yang dikembangkan di Indonesia karena memiliki rasa yang lebih manis dibandingkan jagung biasa. Selain itu umur produksinya lebih singkat (genjah) yaitu $70-80$ hari sehingga sangat menguntungkan (Anonim, 1992). Jenis ini mengandung kadar gula yang relatif tinggi, karena itu biasanya di panen muda untuk dibakar atau direbus. Ciri dari jenis ini adalah bila masak bijinya menjadi keriput.

Tanaman jagung manis akan mencapai hasil yang optimum apabila hara yang dibutuhkan tanaman dalam kondisi yang memadai. Input hara diperoleh dari pemupukan yang biasanya melalui pemberian pupuk kimiawi N, P, dan K. Adapun pupuk anorganik yang direkomendasikan untuk tanaman jagung manis adalah $200 \mathrm{~kg} \mathrm{~N} / \mathrm{ha}, 150 \mathrm{~kg}$ $\mathrm{P}_{2} \mathrm{O}_{5} / \mathrm{ha}$, dan $150 \mathrm{~kg} \mathrm{~K} 2 \mathrm{O} / \mathrm{ha}$ dan bahan organik 10 sampai 20 ton per hektar (Koswara, 1989). Pupuk Urea adalah pupuk kimia yang mengandung Nitrogen $(\mathrm{N})$ berkadar tinggi. Unsur Nitrogen merupakan zat hara yang sangat diperlukan tanaman (Palimbani, 2007). Pupuk Urea bersifat mudah larut dalam air dan sifatnya sangat mudah menghisap air (higroskopis), Hal ini menyebabkan jumlah nitrogen dalam tanah sangat sedikit sedangkan tiap tahun nitrogen yang diambil tanaman sangat banyak (Buckman dan Brady, 1982). Dalam tanaman nitrogen memegang peranan penting dalam merang-sang pertumbuhan organ-organ vegetatif tanaman seperti meningkatkan pertambahan ruas batang. Ruas batang yang bertambah panjang mengakibatkan tanaman jagung manis akan semakin tinggi.

Tinggi tanaman jagung manis dapat mencapai 2,5 meter sehingga pada saat cuaca buruk seperti angin yang bertiup cukup kencang akan menyebabkan tanaman jagung manis rebah sehingga produksi tanaman jagung manis akan turun dan kaulitas buahnya tidak baik karena bersentuhan langsung dengan tanah.

Paclobutrazol adalah suatu retardan dimana menurut Cathey (1975), retardan adalah senyawa organik yang menghambat perpanjangan batang, meningkatkan warna hijau daun dan secara tidak langsung mempengaruhi pembungaan tanpa menyebabkan pertumbuhan abnormal. Weaver (1972) mengemukakan bahwa efek pemberian retardan bervariasi tergantung susunan kimia senyawa dan species tanaman. Paclobutrazol merupakan salah satu retardan yang bila diberikan pada tanaman yang responsif dapat menghambat perpanjangan sel pada meristem sub apikal, mengurangi laju perpanjangan batang tanpa mempengaruhi pertumbuhan dan perkembangan daun. Hasil penelitian Mamarimbing dan Tumewu (2001), pemberian paclobutrazol mempengaruhi tinggi tanaman padi dimana tanaman padi yang diberi paclobutrazol sampai dengan 1500 ppm dapat menekan pertambahan tinggi tanaman padi.

Pemupukan $\mathrm{N}, \mathrm{P}$, dan $\mathrm{K}$ pada tanaman jagung manis akan meningkatkan pertumbuhan tanaman, di samping itu pemberian Paclobutrazol dengan beberapa konsentrasi pada tanaman jagung manis akan mengontrol pertumbuhan tanaman jagung manis. Buckman dan Brady (1969), berpendapat bahwa pupuk nitrogen dapat meningkatkan pertumbuhan dan memberikan warna hijau pada daun, memperbesar butiran pada serealia dan meningkatkan persentase proteinnya.

Berdasarkan uraian di atas maka perlu dilakukan penelitian Pertumbuhan Jagung Manis (Zea mays saccharata) pada Pemberian Paclobutrazol dan pupuk Nitrogen.

\section{METODE PENELITIAN}

Penelitian rumah kaca yang dilaksanakan pada bulan Juli 2011 sampai November 2011 di Rumah Kaca Fakultas Pertanian Unsrat, menggunakan rancangan Rancangan Acak Kelopok (RAK) pola faktorial dengan Faktor I Dosis Pupuk Nitrogen (A) Konsentrasi Paclobutrazol, yang terdiri dari tiga taraf dan faktor II Konsentrasi Paclobutrazol (B) yang terdiri dari tiga taraf. Semua satuan percobaan diulang sebanyak 3 kali. Perlakuan tersebut adalah : Faktor I (A): Dosis pupuk Nitrogen, $A 0=$ tanpa pemupukan, $A 1=100$ $\mathrm{kg} \mathrm{N} / \mathrm{ha}, \quad A 2=200 \mathrm{~kg} \mathrm{~N} / \mathrm{ha}$, Faktor $\|(B)$ : Konsentrasi Paclobutrazol, $\mathrm{Bo}=$ tanpa Paclobutrazol, B1 = 500 ppm, B2 = 1000 ppm. 
Variabel yang diamati adalah : 1) Tinggi Tanaman, diukur dari pangkal batang sampai ujung daun terpanjang. Pengukuran dilaksanakan setiap satu minggu (sejak benih di tanam) sampai $75 \%$ tanaman berbunga. 2) Jumlah daun, dihitung setiap satu minggu (sejak benih di tanam) sampai tanaman $75 \%$ berbunga.

\section{Prosedur Kerja :}

1) Persiapan; pengujian daya tumbuh benih di laboratorium. 2) Pengambilan tanah, tanah di keringanginkan kemudian diayak. 3) Tanah dimasukan ke dalam polibag berukuran $10 \mathrm{~kg}$ tanah. 4) Benih ditanam dimana tiap polibag satu tanaman. 5) Dilakukan pemupukan $\mathrm{N}$ sesuai dosis perlakuan dan pupuk $\mathrm{P}$ dan $\mathrm{K}$ sesuai dosis rekomendasi. 6) Pada saat tanaman berumur 2 minggu, dilakukan penyemprotan paclobutrazol sesuai dosis perlakuan. 7) Pemeliharaan; penyiraman sesuai kebutuhan tanaman. 8) Pengambilan data dilakukan satu minggu setelah tanam dan pengamatan setiap minggu sampai tanaman jagung manis $75 \%$ berbunga.

\section{Analisis Data}

Data dianalisis menggunakan analisis ragam dan dilanjutkan dengan uji BNT pada taraf $5 \%$.

\section{HASIL DAN PEMBAHASAN}

\section{Tinggi Tanaman Jagung Manis}

Hasil sidik ragam menunjukkan bahwa interaksi antara pupuk nitrogen dan paclobutrazol tidak berpengaruh nyata pada tinggi tanaman jagung manis. Pengaruh mandiri paclobutrazol nyata pada tinggi tanaman pengamatan minggu ke V dan VI. Hasil uji BNT 5\% dapat dilihat pada Tabel 1.

Tabel 1 menunjukkan bahwa perlakuan Bo (tanpa paclobutrazol) memberikan tanaman jagung manis tertinggi yang berbeda nyata dengan pemberian paclobutrazol 500 ppm (B1) dan 1000 ppm paclobutrazol (B2) per liter air. Paclobutrazol sebagai Retardan (penghambat pertumbuhan tanaman) pengaruh utamanya adalah untuk memperpendek panjang antar buku dan tinggi tanaman. (Gardner, Pearce, dan Mithcell, 1991). Menurut Wattimena (1987), pengaruh retardan dalam hal ini paclobutrazol terhadap pertumbuhan tanaman adalah menghambat elongasi sel pada sub meristem, memperpendek ruas tanaman, mempertebal batang, mencegah kerebahan, menghambat senesens, memperpanjang masa simpan, meningkatkan pembuahan dan membantu perkecambahan dan pertunasan. Pengaruh retardan di dalam metabolisme tanaman adalah dalam menstimulir aktivitas enzim yang mengkatalisa proses fotosintesis (Thomas, 1979). Hasil penelitian Ani (2000), diperoleh bahwa pemberian 50 ppm dan 100 ppm paclobutrazol dapat menurunkan tinggi tanaman, meningkatkan jumlah klorofil, menurunkan jumlah umbi kelas $A$, B1 dan B2 per plot serta bobot umbi per plot dibandingkan dengan kontrol (tanpa paclobutrazol). Paclobutrazol tergolong zat penghambat tumbuh (growth retardant). Pengaruh fisiologis zat penghambat tumbuh antara lain memperpendek ruas tanaman dan mencegah kerebahan (Watimena, 1987).

Tabel 1. Pengaruh Paclobutrazol Terhadap Tinggi Tanaman Jagung Manis (Zea mays saccharata) (Table 1. Effect of Paclobutrazol Plant Height Of Sweet Corn (Zea mays saccharata))

\begin{tabular}{ccc}
\hline \multirow{2}{*}{ Perlakuan } & \multicolumn{2}{c}{ Rata-rata Tinggi Tanaman Jagung Manis (cm) } \\
\cline { 2 - 3 } & Minggu ke-V & Minggu ke-VI \\
\hline Bo & $144,28 \mathrm{~b}$ & $157,61 \mathrm{~b}$ \\
B1 & $115,28 \mathrm{a}$ & $124,61 \mathrm{a}$ \\
B2 & $106,61 \mathrm{a}$ & $115,89 \mathrm{a}$ \\
\hline BNT 5\% & 16,77 & 12,93 \\
\hline
\end{tabular}

Keterangan : Angka yang diikuti dengan notasi yang sama, tidak berbeda nyata berdasarkan uji BNT 5\%. 


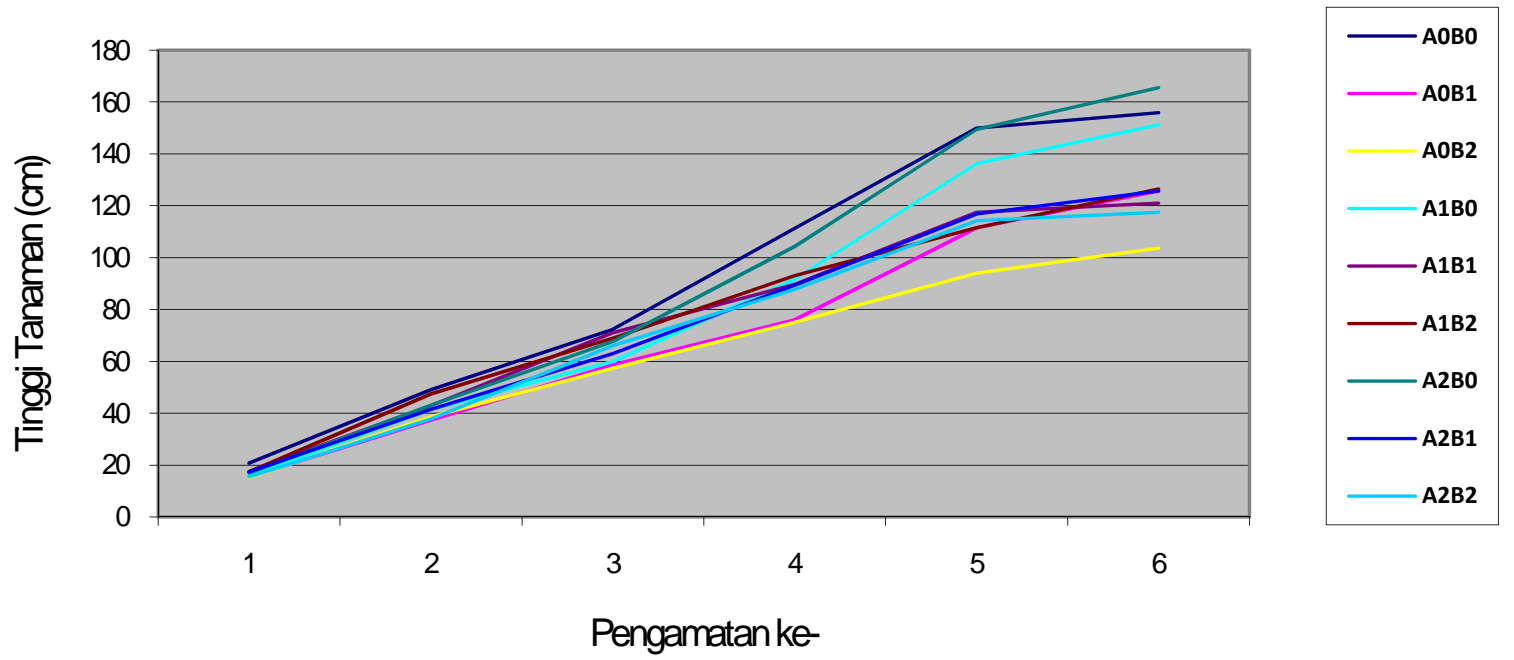

Gambar 1. Grafik Tinggi Tanaman Jagung Manis

(Figure 1. Sweet Corn Plant Height Chart)

Penggunaan Paclobutrazol dengan konsentrasi 500 dan 1000 ppm menyebabkan ruas batang tanaman jagung manis lebih pendek dibandingkan dengan tanpa penggunaan paclobutrazol (Gambar 1). Pendeknya ruas tanaman jagung manis menyebabkan tanaman jagung manis tidak mudah rebah ataupun patah akibat tiupan angin. Pada saat penelitian angin bertiup kencang sehingga beberapa tanaman yang tidak diberi paclobutrazol rebah. Jadi pemberian paclobutrazol mengurangi kerugian panen akibat tiupan angin. Hasil penelitian Ibrahim (2005), pertumbuhan tunas bangle (Zingiber purpureum
Roxb) dalam penyimpanan secara in vitrro menunjukkan bahwa semakin tinggi konsentrasi paclobutrazol jumlah tunas, daun, dan akar semakin rendah tanaman menjadi pendek.

\section{Jumlah Daun Tanaman Jagung Manis}

Hasil sidik ragam menunjukkan bahwa interaksi antara pupuk nitrogen dan paclobutrazol berpengaruh nyata pada jumlah daun tanaman jagung manis pada pengamatan minggu ke $\mathrm{Vl}$. Hasil uji BNT 5\% dapat dilihat pada Tabel 2.

Tabel 2. Pengaruh Pupuk Nitrogen dan Paclubutrazol Terhadap Jumlah Daun Tanaman Tanaman Jagung Manis (Zea mays saccharata)

(Table 2. Effect of Nitrogen Fertilizer and Crop Leaf to Total Paclubutrazol Sweet Corn plants (Zea mays saccharata))

\begin{tabular}{cc}
\hline Perlakuan & Rata-rata Jumlah Daun Tanaman Jagung Manis \\
\hline AoBo & $13,00 \mathrm{bc}$ \\
AoB1 & $11,67 \mathrm{a}$ \\
AoB2 & $14,00 \mathrm{c}$ \\
A1Bo & $12,00 \mathrm{ab}$ \\
A1B1 & $13,00 \mathrm{bc}$ \\
A1B2 & $13,33 \mathrm{bc}$ \\
A2Bo & $13,67 \mathrm{c}$ \\
A2B1 & $11,33 \mathrm{a}$ \\
A2B2 & $13,33 \mathrm{bc}$ \\
\hline BNT 5\% & 1,30 \\
\hline
\end{tabular}

Keterangan : Angka yang diikuti dengan notasi yang sama, tidak berbeda nyata berdasarkan uji BNT 5\%. 


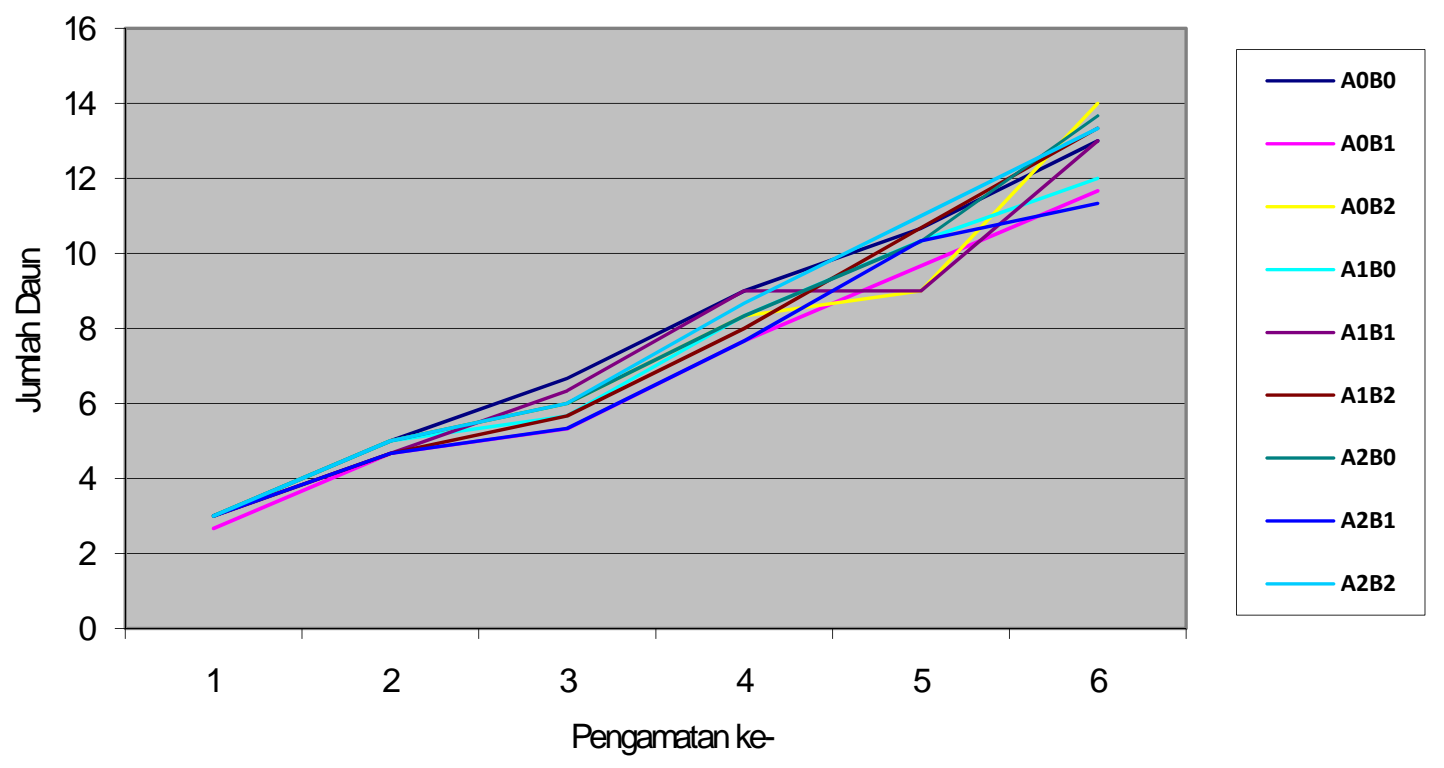

Gambar 2. Grafik Jumlah Daun Tanaman Jagung Manis

(Figure 2. Graph Number of Leaves Plant Sweet Corn)

Tabel 2 menunjukkan bahwa perlakuan Interaksi antara pupuk Nitrogen dan paclobutrazol yaitu AoB2 memberikan jumlah daun terbanyak yang tidak berbeda nyata dengan perlakuan $\mathrm{AoB} o$, $A 1 B 1, A 1 B 2, A 2 B 0$, dan A2B2. Sedangkan Jumlah daun paling sedikit pada perlakuan a2B1 yang tidak berbeda nyata dengan perlakuan A1Bo dan AoB1. Dari data jumlah daun peranan pupuk nitrogen dan paclobutrazol sama dengan yang tidak diberi pupuk nitrogen dan paclobutrazol. Hal ini berarti pemberian paclobutrazol dan pupuk nitrogen memberikan jumlah daun yang sama dengan tanpa pemberian paclobutrazol dan pupuk nitrogen. Menurut Gardner dkk. (1991), jumlah dan ukuran daun dipengaruhi oleh genotype dan lingkungan. Hal ini mungkin disebabkan karena adanya daundaun tua yang sudah kering bahkan pelepah daun sudah lepas dari batang jagung sehingga tidak terhitung lagi. Juga daun-daun bagian bawah tanaman jagung pada akhirnya akan gugur akibat umur tanaman.

\section{KESIMPULAN}

Pengaruh interaksi antara pupuk nitrogen dan paclobutrazol tidak nyata terhadap tinggi tanaman jagung manis. Secara mandiri paclobutrazol mempengaruhi tinggi tanaman jagung manis. Pemberian paclobutrazol 500 ppm dan 1000 ppm memberikan tanaman jagung lebih pendek dibandingkan dengan tanpa paclobutrazol. Interaksi pupuk nitrogen dan paclobutrazol berpengaruh nyata pada jumlah daun tanaman jagung manis.

\section{DAFTAR PUSTAKA}

Anonimous. 1992. Hasil Penelitian Tanaman Pangan. Prosiding Seminar Balittan Bogor. 29 Pebruari dan 2 Maret 1992. Volume 1. Badan Penelitian dan Pengembangan Pertanian Balai Penelitian Tanaman Pangan Bogor.

Ani, N. 2000. Pengaruh Konsentrasi Paclobutrazol dan Urea pada stek Kentang Terhadap Produksi Tuberlet Varietas Granola. http://www.google.co.id/url?sa=t\&rct=j\&q=

\&esrc $=s \&$ source $=$ web $\& c d=4 \&$ ved $=0 C C 4 Q$ FiAD\&url=http\%3A\%2F\%2Frepository.usu .ac.id\%2Fbitstream\%2F123456789\%2F15 496\%2F1\%2Fkpt-apr2004-\%2520\%288\% 29.pdf\&ei=6zs6UM7IPI prQe-woCwDg\& usg=AFQjCNHQZNMCuyjhXmLhFHR9nM CrSOizog\&sig2=2y a6uYHhSOk8VjitEAH vA. Diakses 12 Desember 2011. 
Buckman H. O. Dan N. C. Brady. 1969. The Nature and Properties of Soils. The Mc. Millan Co., Inc. New York.

Cathey, H. M. 1975. Comparative Plant Growth Retarding Aktivities of Ancymidol ACPC, Phosphor, Chlormequat and SDH on Ornamental Plant Species. Hort. Sci. 10 (3) : 204-206.

Dwidjoseputro. 1992. Pengantar Fisiologi Tumbuhan. PT. Gramedia Jakarta.

Gardner, F. P., R. B. Pearce dan R. L. Mitchell. 1991. Fisiologi Tanaman Budidaya. Penerbit Universitas Indonesia Jakarta.

http://www.pupukkaltim.com/ina/produk/index.php? act:urea. Pupuk Urea. Diakses tanggal 25 Agustus 2010.

Ibrahim, M.S.D. 2005. Pengaruh Pemberian Paclobutrazol Terhadap Pertumbuhan Bangle (Zingiber purpureum Roxb) dalam Penyimpanan In-Vitro. Buletin TRO Vol. $X V I$, No. 2. http://minyakatsiriindonesia. wordpress.com/budidaya-bangle/abstrakpenelitian/. Diakses tanggal 12 November 2011.
Koswara, J. 1982. Budidaya Jagung. Bahan Penataran. Bogor.

Palimban1. 2007. Mengenal pupuk Urea. http://pusri.wordpress.com/2007/09/22/me ngenal-pupuk-urea/. Diakses tanggal 13 Desember 2011.

Wattimena, G. A. 1987. Zat Pengatur Tumbuh Tanaman. Laboratorium Kultur Jaringan, PAU Bioteknologi IPB Bogor. http://www.google.co.id/url?sa=t\&rct=j\&q= \&esrc $=s \&$ source $=$ web \&cd $=4 \&$ ved $=0 C C 4 Q$ FjAD\&url=http\%3A\%2F\%2Frepository.usu .ac.id\%2Fbitstream\%2F123456789\%2F15 496\%2F1\%2Fkpt-apr2004-

\%2520\%288\%29.pdf\&ei=6zs6UM7IPI prQ e-woCwDg\&usg=AFQjCNHQZNMCuyjhX mLhFHR9nMCrSOizog\&sig2=2y_a6uYHh SOk8VjitEAHvA 
Lampiran 1. Sidik Ragam Tinggi Tanaman Jagung Manis Minggu I

\begin{tabular}{lccccc} 
Sumber & db & Jumlah & Kuadrat & F Hitung & F Tabel 5\% \\
\hline Kelompok & 2 & 6,280762 & 3,140381 & 0,5405 & 3,63 \\
Perlakuan & 8 & 71,853676 & 8,981709 & 1,5458 & 2,59 \\
Faktor I (A) & 2 & 1,424859 & 0,712429 & $0,1226 \mathrm{~ns}$ & 3,63 \\
Faktor II (B) & 2 & 16,180935 & 8,090467 & $1,3924 \mathrm{~ns}$ & 3,63 \\
Interaksi & 4 & 54,247883 & 13,561971 & $2,3341 \mathrm{~ns}$ & 3,01 \\
Galat & 16 & 92,966148 & 5,810384 & & \\
- & & & & & \\
Total & 26 & 171,100586 & & & \\
-
\end{tabular}

$\mathrm{KK}=14,33 \%$

Keterangan $:$ ns $=$ non significant

Lampiran 2. Sidik Ragam Tinggi Tanaman Jagung Manis Minggu II

\begin{tabular}{|c|c|c|c|c|c|}
\hline Sumber & $\mathrm{db}$ & Jumlah & Kuadrat & F Hitung & F Tabel $5 \%$ \\
\hline Kelompok & 2 & 163,462677 & 81,731339 & 2,2478 & 3,63 \\
\hline Perlakuan & 8 & 401,210938 & 50,151367 & 1,3793 & 2,59 \\
\hline Faktor I (A) & 2 & 48,938370 & 24,469185 & $0,6730 \mathrm{~ns}$ & 3,63 \\
\hline Faktor II (B) & 2 & 81,382813 & 40,691406 & $1,1191 \mathrm{~ns}$ & 3,63 \\
\hline Interaksi & 4 & 270,889771 & 67,722443 & $1,8626 \mathrm{~ns}$ & 3,01 \\
\hline Galat & 16 & 92,966148 & 36,360001 & & \\
\hline Total & 26 & 1146,433594 & & & \\
\hline
\end{tabular}

$\mathrm{KK}=14,33 \%$

Keterangan : ns $=$ non significant

Lampiran 3. Sidik Ragam Tinggi Tanaman Jagung Manis Minggu III

\begin{tabular}{lccccc} 
Sumber & db & Jumlah & Kuadrat & F Hitung & F Tabel 5\% \\
\hline Kelompok & 2 & 1220,222168 & 610,111084 & 5,2245 & 3,63 \\
Perlakuan & 8 & 725,333313 & 90,666664 & 0,7764 & 2,59 \\
Faktor I (A) & 2 & 72,222221 & 36,111111 & $0,3092 \mathrm{~ns}$ & 3,63 \\
Faktor II (B) & 2 & 37,555557 & 18,777779 & $0,1608 \mathrm{~ns}$ & 3,63 \\
Interaksi & 4 & 615,555542 & 153,888885 & $1,3178 \mathrm{~ns}$ & 3,01 \\
Galat & 16 & 1868,444580 & 116,777786 & & \\
\hline Total & 26 & 3814,000000 & & & \\
-
\end{tabular}

$\mathrm{KK}=16,63 \%$

Keterangan $: \mathrm{ns}=$ non significant 
Lampiran 4. Sidik Ragam Tinggi Tanaman Jagung Manis Minggu IV

\begin{tabular}{|c|c|c|c|c|c|}
\hline Sumber & $\mathrm{db}$ & Jumlah & Kuadrat & F Hitung & F Tabel $5 \%$ \\
\hline Kelompok & 2 & 2179,560791 & 1089,780396 & 4,0907 & 3,63 \\
\hline Perlakuan & 8 & 3276,671875 & 409,583984 & 1,5375 & 2,59 \\
\hline Faktor I (A) & 2 & 184,671875 & 92,335938 & $0,3466 \mathrm{~ns}$ & 3,63 \\
\hline Faktor II (B) & 2 & 1802,894043 & 901,447021 & $3,3838 \mathrm{~ns}$ & 3,63 \\
\hline Interaksi & 4 & 1289,105957 & 322,276489 & 1,2079 ns & 3,01 \\
\hline Galat & 16 & 4262,439453 & 266,402466 & & \\
\hline Total & 26 & 9718,671875 & & & \\
\hline
\end{tabular}

$\mathrm{KK}=17,96 \%$

Keterangan $: \mathrm{ns}=$ non significant

Lampiran 5. Sidik Ragam Tinggi Tanaman Jagung Manis Minggu V

\begin{tabular}{|c|c|c|c|c|c|}
\hline Sumber & $\mathrm{db}$ & Jumlah & Kuadrat & F Hitung & F Tabel 5\% \\
\hline Kelompok & 2 & 912,711792 & 456,355896 & 1,6202 & 3,63 \\
\hline Perlakuan & 8 & 8563,656250 & 1070,457031 & 3,8003 & 2,59 \\
\hline Faktor I (A) & 2 & 321,711792 & 160,855896 & $0,5711 \mathrm{~ns}$ & 3,63 \\
\hline Faktor II (B) & 2 & 7410,656250 & 3705,328125 & 13,1547 * & 3,63 \\
\hline Interaksi & 4 & 831,288208 & 207,822052 & $0,7378 \mathrm{~ns}$ & s $\quad 3,01$ \\
\hline Galat & 16 & 4506,788086 & 281,674255 & & \\
\hline Total & 26 & 13983,156250 & & & \\
\hline
\end{tabular}

$\mathrm{KK}=13,71 \%$

Keterangan $: \mathrm{ns}=$ non significant

Lampiran 6. Sidik Ragam Tinggi Tanaman Jagung Manis Minggu VI

\begin{tabular}{|c|c|c|c|c|c|}
\hline Sumber & $\mathrm{db}$ & Jumlah & Kuadrat & F Hitung & F Tabel 5\% \\
\hline Kelompok & 2 & 685,552063 & 342,776031 & 2,0463 & 3,63 \\
\hline Perlakuan & 8 & 9941,801758 & 1242,725220 & 7,4189 & 2,59 \\
\hline Faktor I (A) & 2 & 274,440979 & 137,220490 & 0,8192 ns & 3,63 \\
\hline Faktor II (B) & 2 & 8791,774414 & 4395,887207 & 26,2430 * & 3,63 \\
\hline Interaksi & 4 & 875,586365 & 218,896591 & $1,3068 \mathrm{~ns}$ & 3,01 \\
\hline Galat & 16 & 2680,114990 & 167,507187 & & \\
\hline Total & 26 & 13307,468750 & & & \\
\hline
\end{tabular}

$\mathrm{KK}=9,77 \%$

Keterangan $: \mathrm{ns}=$ non significant 
Lampiran 7. Sidik Ragam Jumlah Daun Tanaman Jagung Manis Minggu II

\begin{tabular}{lccccc} 
Sumber & $d b$ & Jumlah & Kuadrat & F Hitung & F Tabel 5\% \\
\hline Kelompok & 2 & 0,518521 & 0,259260 & 1,9310 & 3,63 \\
Perlakuan & 8 & 0,740743 & 0,092593 & 0,6897 & 2,59 \\
Faktor I (A) & 2 & 0,074076 & 0,037038 & $0,2759 \mathrm{~ns}$ & 3,63 \\
Faktor II (B) & 2 & 0,518521 & 0,259260 & $1,9310 \mathrm{~ns}$ & 3,63 \\
Interaksi & 4 & 0,148146 & 0,037036 & $0,2759 \mathrm{~ns}$ & 3,01 \\
Galat & 16 & 2,148146 & 0,134259 & & \\
- & & & & & \\
Total & 26 & 3,407410 & & &
\end{tabular}

$\mathrm{KK}=7,55 \%$

Keterangan $: \mathrm{ns}=$ non significant

Lampiran 8. Sidik Ragam Jumlah Daun Tanaman Jagung Manis Minggu III

\begin{tabular}{lccccc} 
Sumber & db & Jumlah & Kuadrat & F Hitung & F Tabel 5\% \\
\hline Kelompok & 2 & 13,555576 & 6,777788 & 10,3830 & 3,63 \\
Perlakuan & 8 & 4,666687 & 0,583336 & 0,8936 & 2,59 \\
Faktor I (A) & 2 & 0,222243 & 0,111121 & 0,1702 & 3,63 \\
Faktor II (B) & 2 & 0,888909 & 0,444455 & 0,6809 & 3,63 \\
Interaksi & 4 & 3,555535 & 0,888884 & 1,3617 & 3,01 \\
Galat & 16 & 10,444424 & 0,652776 & & \\
- & 16 & & & & \\
Total & 26 & 28,666687 & & &
\end{tabular}

$\mathrm{KK}=13,72 \%$

Keterangan $: \mathrm{ns}=$ non significant

Lampiran 9. Sidik Ragam Jumlah Daun Tanaman Jagung Manis Minggu IV

\begin{tabular}{|c|c|c|c|c|c|}
\hline Sumber & $\mathrm{db}$ & Jumlah & Kuadrat & F Hitung & F Tabel $5 \%$ \\
\hline Kelompok & 2 & 6,000000 & 3,000000 & 2,6667 & 3,63 \\
\hline Perlakuan & 8 & 6,000000 & 0,750000 & 0,6667 & 2,59 \\
\hline Faktor I (A) & 2 & 0,222222 & 0,1111111 & 0,0988 & 3,63 \\
\hline Faktor II (B) & 2 & 0,888889 & 0,444444 & 0,3951 & 3,63 \\
\hline Interaksi & 4 & 4,888889 & 1,222222 & 1,0864 & 3,01 \\
\hline Galat & 16 & 18,000000 & 1,125000 & & \\
\hline Total & 26 & 30,000000 & & & \\
\hline
\end{tabular}


Lampiran 10. Sidik Ragam Jumlah Daun Tanaman Jagung Manis Minggu V

\begin{tabular}{|c|c|c|c|c|c|}
\hline Sumber & $\mathrm{db}$ & Jumlah & Kuadrat & F Hitung & F Tabel $5 \%$ \\
\hline Kelompok & 2 & 0,666748 & 0,333374 & 0,3077 & 3,63 \\
\hline Perlakuan & 8 & 12,666748 & 1,583344 & 1,4616 & 2,59 \\
\hline Faktor I (A) & 2 & 2,888970 & 1,444485 & 1,3334 ns & 3,63 \\
\hline Faktor II (B) & 2 & 2,888970 & 1,444485 & 1,3334 ns & 3,63 \\
\hline Interaksi & 4 & 6,888807 & 1,722202 & $1,5897 \mathrm{~ns}$ & 3,01 \\
\hline Galat & 16 & 17,333252 & 1,083328 & & \\
\hline Total & 26 & 30,666748 & & & \\
\hline
\end{tabular}

$\mathrm{KK}=10,29 \%$

Keterangan $: \mathrm{ns}=$ non significant

Lampiran 11. Sidik Ragam Jumlah Daun Tanaman Jagung Manis Minggu VI

\begin{tabular}{|c|c|c|c|c|c|}
\hline Sumber & $\mathrm{db}$ & Jumlah & Kuadrat & F Hitung & F Tabel $5 \%$ \\
\hline Kelompok & 2 & 2,296441 & 1,148221 & 2,0329 & 3,63 \\
\hline Perlakuan & 8 & 20,740885 & 2,592611 & 4,5903 & 2,59 \\
\hline Faktor I (A) & 2 & 0,074219 & 0,037109 & 0,0657 ns & 3,63 \\
\hline Faktor II (B) & 2 & 10,963108 & 5,481554 & 9,7052 * & 3,63 \\
\hline Interaksi & 4 & 9,703558 & 2,425889 & 4,2951 * & 3,01 \\
\hline Galat & 16 & 9,036893 & 0,564806 & & \\
\hline Total & 26 & 32,074219 & & & \\
\hline
\end{tabular}

$\mathrm{KK}=5,86 \%$

Keterangan $: \mathrm{ns}=$ non significant 